\title{
IL28B and ITPA Single Nucleotide Polymorphisms in a Cohort of Patients with HCV and HCV/HIV, Southern Brazil
}

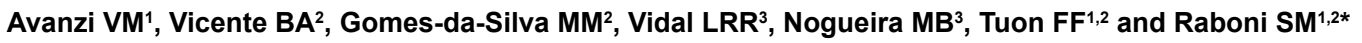

${ }^{1}$ Postgraduate Program in Internal Medicine and Health Science, Universidade Federal do Paraná, Brazil

2Infectious Diseases Division, Universidade Federal do Paraná, Brazil

${ }^{3}$ Laboratory of Virology, Universidade Federal do Paraná, Brazil

\begin{abstract}
Objective: The aim of this study is to describe the single nucleotide polymorphisms (SNP) in human genes for IL28B and ITPA of HIV/HCV coinfected patients followed at a referral Hospital of Universidade Federal do Paraná (UFPR).

Methods: A cross-sectional study was carried out. HIV/HCV coinfected and HCV monoinfected patients were enrolled. Clinical and epidemiological data from medical records were reviewed, and peripheral blood was collected to analyze the IL28B and ITPA SNPs.

Results: A total of $37 \mathrm{HCV}$ - and $41 \mathrm{HCV} / \mathrm{HIV}$-positive subjects were included in the study, 13 (35.1\%) monoinfected subjects were previously treated, $12(92.3 \%)$ with PEG-INFa/RBV and of these, $8(61.5 \%)$ had sustained virological response (SVR). Regarding HCV/HIV coinfected patients, 23 (56.1\%) received treatment with PEG-INFa/RBV and $12(52.1 \%)$ had SVR. IL28B CC genotype was found in all HCV monoinfected patients and in $56.5 \%$ of coinfected subjects. Regarding ribavirin-induced anemia, all patients showed the ITPA SNP favorable for this event, and anemia was present in $38.5 \%$ of monoinfected and in $65.2 \%$ of coinfected patients.

Conclusion: With the availability of direct-acting antivirals (DAAs) for the treatment of chronic infection by the hepatitis $\mathrm{C}$ virus, free-INF regimens have been implemented worldwide. However, in the setting of HIV/HCV coinfection ribavirin will continue to compose some therapeutic schemes. Thus, tests related to genetic markers that influence the response to HCV treatment should be recommended in pretreatment, since results would benefit both the patient and the public healthcare system, guiding rational drug use in situations where responses to treatment are particularly low and adverse effects are high.
\end{abstract}

Keywords: Coinfection; HIV/HCV; HIV; HCV; SNP; IL28B; ITPA

\section{Background}

The prevalence of HIV/HCV coinfection in Brazil ranges from $3.3 \%$ to $82.4 \%$ with average of $20.3 \%$ [1]. HIV/HCV coinfection is a significant risk factor for liver fibrosis, since HIV seropositivity and low CD4+ counts seem to accelerate this process [2,3]. In addition, HCV infection has been shown to be associated with faster progression to acquired immunodeficiency syndrome (AIDS) [4]. Until 2011, the standard treatment of chronic hepatitis $C$ consisted of a combination of pegylated-interferon-alpha plus ribavirin (PEG-INFa/RBV).

Currently, a new era in the treatment of chronic HCV infection began with the approval of direct-acting antiviral drugs (DAAs) oral medications in interferon-free regimens. However, in HIV/HCV coinfection the PEG$\mathrm{INF} \alpha / \mathrm{RBV}$ combination remains recommended [5].

Therefore, the evaluation of prediction of sustained virological response (SVR) to PEG-INFa based therapy must be maintained seeking to identify patients with high chance to cure and, consequently, candidates for this therapy and those with low chance to respond to PEG-INFa/RBV, candidates for interferon-free therapies. Moreover, treatment failure is likely to occur due to inherent viral and host factors such as the presence of certain SNPs and inappropriate drug regimens [6] and deeper analysis of non-response may help elucidate its molecular mechanisms [7].

In this setting, genetic variation in interleukin 28B (IL28B) and inosine triphosphatase (ITPA) genes are known host genetic factors that play a vital role in the clearance of $\mathrm{HCV}$ infection and in the risk of ribavirin-induced hematologic toxicity, respectively [8]. Currently, with reports of therapeutic failure to DAAs, it has been recommended to evaluate viral and host factors predictors of treatment efficacy, among which are cited resistance-associated variants (RAVs) detection and IL28B SNPs [9]. Besides that, data on HIV/HCV coinfected patients and the impact of host IL28B and ITPA SNPs on treatment response and toxicity in Brazilian patients are scarce. In this study we describe the epidemiological, genetic and clinical profile of a cohort of HIV/ HCV coinfected patients in follow up in a tertiary care academic hospital in Southern Brazil.

\section{Methods}

\section{Study subjects}

A cross-sectional study was carried out, in which HIV/HCV coinfected outpatients identified in reference clinics of Hospital de Clínicas - Universidade Federal do Paraná (HC/UFPR) were prospectively included from March 2011 to April 2016. HCV or HIV/

*Corresponding author: Raboni SM, Infectious Diseases Division, Universidade Federal do Paraná, Rua General Carneiro, 180, 3rd floor, 82060-900 Curitiba, PR, Brazil, Tel: +55 41 33607974; Fax: +55 41 33601811; E-mail: sraboni@ufpr.br

Received July 25, 2016; Accepted August 11, 2016; Published August 18, 2016

Citation: Avanzi VM, Vicente BA, Gomes-da-Silva MM, Vidal LRR, Nogueira MB et al. (2016) IL28B and ITPA Single Nucleotide Polymorphisms in a Cohort of Patients with HCV and HCV/HIV, Southern Brazil. J AIDS Clin Res 7: 610. doi: 10.4172/2155-6113.1000610

Copyright: (c) 2016 Avanzi VM, et al. This is an open-access article distributed under the terms of the Creative Commons Attribution License, which permits unrestricted use, distribution, and reproduction in any medium, provided the original author and source are credited. 
HCV coinfected patients were enrolled in the study. Patients with incomplete medical information, children and those who did not agree to participate in the study were excluded. All information related to clinical, demographics and epidemiological data were obtained through a structured questionnaire and medical record reviews. Included patients were submitted to a collection of $5 \mathrm{~mL}$ venous blood. The Institutional Review Board of HC/UFPR approved the study (IRB\# 34716414.9.0000.0096).

\section{Genotyping}

The SNP rs12979860 in the region of the IL28B gene was carried out by confronting two-pair primers (CTPP), as previously reported [10]. SNPs rs1127354 and rs7270101 in chromosome 20 for ITPA gene were performed using the ABI TaqMan allelic discrimination kit and the ABI7900HT Sequence Detection System (Applied Biosystems Inc., Foster City, CA, USA), as previously described [11]. The possible genotypes for each biallelic polymorphism are rs1127354: C/C, A/C, A/A (minor allele=A); rs7270101: A/A, A/C, C/C (minor allele=C). ITPase activity was defined by the presence of minor alleles at the respective polymorphic sites $[11,12]$. ITPA deficiency has been grouped into none; mild ( $>60 \%$ activity); moderate (30-60\% activity); and severe ( $<30 \%$ activity).

\section{Statistical analyses}

Demographics, epidemiological, clinical and genetic data were compiled and analyzed using GraphPad Prism software version 5.03 (Graph Pad Software Inc., La Jolla, CA, USA). Baseline demographics and clinical characteristics with normal and non-normal distributions were presented as means \pm standard deviations and medians with interquartile ranges (IQR), respectively. The Fisher's exact test, quisquared test, or Wilcoxon-Mann-Whitney test were used where appropriate. The significance level was set at $\mathrm{P}<0.05$.

\section{Results}

A total of $37 \mathrm{HCV}$ - and $41 \mathrm{HCV} / \mathrm{HIV}$-positive subjects were included in the study. The demographics, clinical and virological data of the study population are described in Table 1. Regarding HCV therapy, 13 (35\%) monoinfected subjects were treated, 12 (92\%) with PEG-INFa/RBV and one $(8 \%)$ with simeprevir and sofosbuvir. Among treated patients, 8 (61.5\%) had SVR, 4 (31\%) had null response and 1 (8\%) relapsed. Only $2(15 \%)$ patients had liver biopsy and both presented fibrosis. Regarding HCV/HIV coinfected patients, 23 (56\%) were treated for HCV with PEGINF $\alpha /$ RBV. Of these, 12 (52\%) had SVR, 9 (39\%) had null response and 2 (9\%) relapsed. Twenty (49\%) patients had liver biopsy and 18 (90\%) had fibrosis, $14(70 \%)$ had hepatic steatosis, $6(30 \%)$ presented cirrhosis, and only one (5\%) showed no liver disorders. Additionally, 3 (7\%) patients died, two due to liver complications. The results of the IL28B genotype (SNP rs12979860) and the relationship with the response to treatment, as well as the genotype for ITPA SNPs (rs7270101 and rs1127354) and the ribavirin-induced anemia are shown in Figure 1. The predicted ITPase activity distribution according to compound genotype of rs7270101 and rs1127354, as previously determined by biochemical analyses, is shown in Table 2.

\section{Discussion}

The efficacy of PEG-INFa/RBV treatment depends, in part, on the interaction of virus and host factors [13], and SNPs may be associated with the outcome and response to treatment, specially IL28B and ITPA genotypes have been reported to be significant markers in recent trials $[14,15]$. For IL28B SNPs, SVR rates were higher in CC patients (54\% in monoinfected patients and $67 \%$ in coinfected patients), findings similar to those reported in other studies [16-18]. Despite that, no significance was found, probably as a consequence of the small number of patients in both groups.

\begin{tabular}{|c|c|c|c|}
\hline \multirow[t]{2}{*}{ Characteristics } & Monoinfected HCV $(n=37)$ & Coinfected HCV/HIV-1 (n=41) & p-value \\
\hline & $\mathbf{N}(\%)$ & $\mathbf{N}(\%)$ & \\
\hline \multicolumn{4}{|l|}{ Gender } \\
\hline Male & $21(57)$ & $28(68)$ & 0.3515 \\
\hline Female & $16(43)$ & $13(32)$ & \\
\hline Age (Years/Median/IQR ) & $54(40-78)$ & $49(46-75)$ & 0.3755 \\
\hline Hepatitis diagnosis time (Years/Median/IQR) & $2(1-21)$ & $10(7-23)$ & $<0.0001$ \\
\hline \multicolumn{4}{|l|}{ HCV genotype } \\
\hline 1 & $18(49)$ & $25(61)$ & \multirow[t]{2}{*}{0.1306} \\
\hline 3 & $15(41)$ & $9(22)$ & \\
\hline Other $^{1}$ & 0 & $2(5)$ & \\
\hline NG & $4(10)$ & $5(12)$ & \\
\hline \multicolumn{4}{|l|}{ HCV therapy } \\
\hline Yes & $13(35)$ & $23(56)$ & 0.0733 \\
\hline PEG/RIB & $12(92)$ & $23(100)$ & \\
\hline Other $^{2}$ & $1(8)$ & 0 & \\
\hline No & $24(65)$ & $18(44)$ & \\
\hline HIV-1 diagnosis time (Years/Median/IQR) & - & $15(11-25)$ & - \\
\hline ART use & & $41(100)$ & - \\
\hline \multicolumn{4}{|l|}{ HIV-1 viral load } \\
\hline Detectable (>40 copies $/ \mathrm{mL}$ ) & - & $9(22.0)$ & - \\
\hline Undetectable (<40 copies/mL) & - & $32(78.0)$ & - \\
\hline \multicolumn{4}{|l|}{ CD4+ LT value (cell/mm³/ median/IQR) } \\
\hline Nadir & - & $149(83-445)$ & - \\
\hline Current & - & $447(290-1038)$ & - \\
\hline
\end{tabular}

IQR: Interquartile Range; NI: Not Informed; NG: Not Genotyped; Other ${ }^{1}$ : Genotyping 2 And 4; Other²: Simeprevir/Sofosbuvir; ART: Antiretroviral Therapy; In Bold: Significant Difference 
Citation: Avanzi VM, Vicente BA, Gomes-da-Silva MM, Vidal LRR, Nogueira MB, et al. (2016) IL28B and ITPA Single Nucleotide Polymorphisms in a Cohort of Patients with HCV and HCV/HIV, Southern Brazil. J AIDS Clin Res 7: 610. doi: 10.4172/2155-6113.1000610

IL28B rs12979860 SNP x Response to treatment
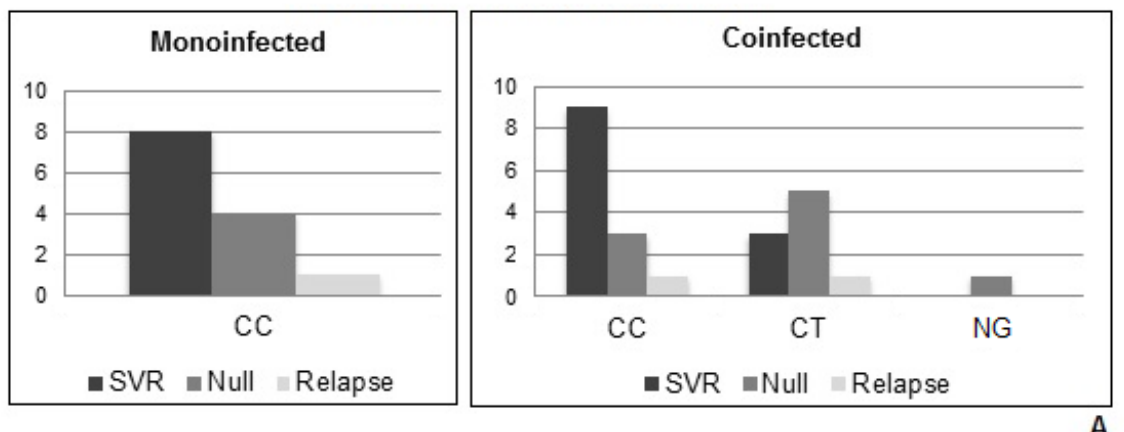

ITPA rs7270101 SNP x Anemia
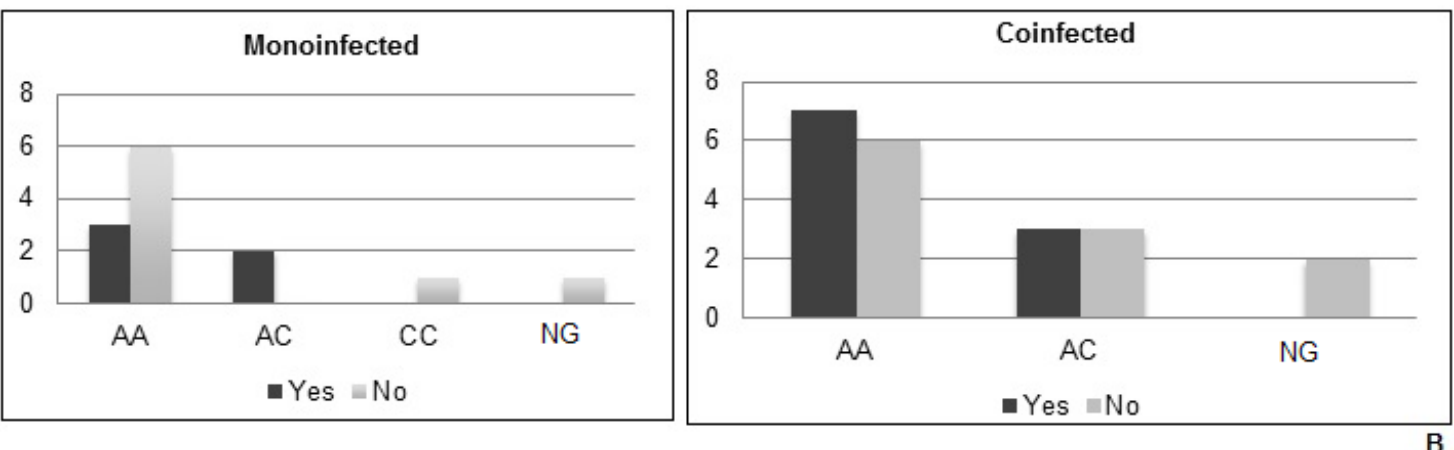

ITPA rs1127354 SNP x Anemia
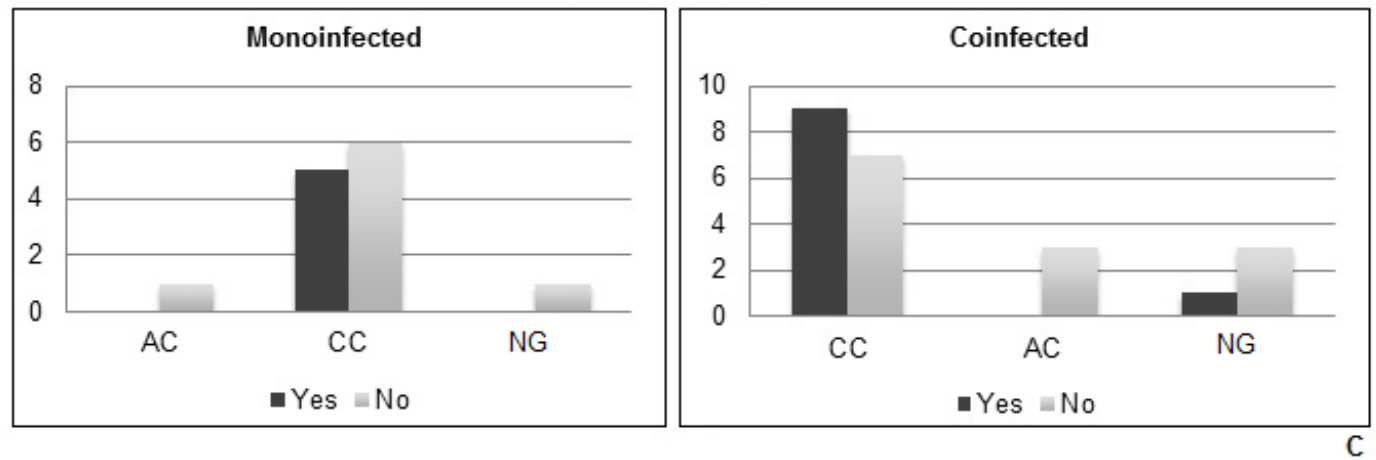

Figure 1: IL28B and ITPA polymorphism, response to treatment and anemia in HCV monoinfected and HCV/HIV coinfected patients. A. IL28B rs12979860 SNP and response to treatment. B. ITPA rs7270101 SNP and anemia. C. ITPA rs1127354 SNP and anemia.

\begin{tabular}{|c|c|c|c|c|c|c|c|}
\hline rs $\mathbf{7 2 7 0 1 0 1}$ & rs $\mathbf{1 1 2 7 3 5 4}$ & Predicted ITPase Activity (\%) & Predicted ITPase Deficiency & HCV & Anemia (\%) & HCV/HIV & Anemia (\%) \\
\hline AA & CC & 100 & - & 7 & $3(43)$ \\
\hline AC & CC & 60 & + & 3 & $2(67)$ \\
\hline AA & CA & 30 & ++ & 12 & 0 \\
\hline CC & CC & 30 & ++ & 1 & 0 \\
\hline AC & CA & 10 & +++ & 0 & 0 \\
\hline AA & AA & $<5$ & +++ & 0 & 0 \\
\hline
\end{tabular}

Note: Definition of an ITPase deficiency is variable according to rs7270101/rs1127354 genotypes: severity of ITPase deficiency was predicted as absent, representing wild type activity $(-)$, mild $(+)$, moderate $(++)$, or severe $(+++)$ deficiency, according to previously study (31)

Table 2: Distribution of predicted ITPase activity according to compound genotype of rs 7270101 and rs 1127354 as previously determined by biochemical analyses in monoinfected (HCV) and coinfected (HCV/HIV) patients.

Previously, Bertol et al. [19] evaluated the frequency of CC genotype in Southern Brazil, it was found in $31 \%$ of HCV monoinfected and 23.5\% of HIV/HCV patients. SVR was not evaluated.
It has been suggested that SNPs close to the IL28B gene have significant influence on the establishment of $\mathrm{HCV}$ infection in monoinfected patients, contributing to a better understanding of the 
susceptibility, natural history of HCV infection, and high rate of SRV in this patient group [16]. However, in the setting of HIV infection, Martin et al. [20] and Nattermann et al. did not find any correlation between the SNP rs12979860 and HIV monoinfected patients; there was no significant difference in the susceptibility to HIV infection, disease progression, or the clinical and laboratory parameters, such as viral load. Therefore, SNPs of the IL28B gene seem to be associated with HIV patients only when they are coinfected with HCV [21].

The ITPA gene encodes inosine triphosphate (ITPase) that catalyzes the conversion of inosine triphosphate (ITP) to inosine monophosphate (IMP) and pyrophosphate (Pi), and thus the ITP does not accumulate in normal cells. ITP is used to keep the adenosine triphosphate (ATP) in red blood cells, consequently preventing oxidative stress. The ITPase deficiency interrupts this cycle, leading to an accumulation of ITP in cells $[22,23]$. The RBV is incorporated into erythrocytes, undergoing phosphorylation to its pharmacologically active form through adenosine kinase. The ribavirin triphosphate is unable to cross the cell membrane of erythrocytes and accumulates intracellularly, thus causing oxidative damage and leading to hemolysis [24]. The ITPase deficiency causes the ITP accumulation in erythrocytes that can compete with RBV triphosphate, consequently protecting the RBVinduced hemolysis [25-27].

ITPase activity modulates the association between RBV and hemolysis, but there is no correlation with hemoglobin $(\mathrm{Hb})$ decline, which has no impact on treatment response. Models suggest that ITPase activity has no direct influence on treatment response. The data confirm the strong protective effect of ITPase deficiency against $\mathrm{Hb}$ decline during PEG-INFa/RBV treatment. Furthermore, ITPase deficiency was associated with a higher cumulative RBV dosage, and yet was not associated with SVR [28].

In this study, all patients treated and genotyped for ITPA SNPs had at least one favorable genotype for the development of anemia. Among monoinfected patients, $42 \%$ had anemia caused by ribavirin and $45 \%$ of coinfected patients presented this event. In a study performed by Delvaux et al. [29] in Brazilian patients with HCV, the allelic distribution frequency of SNPs in rs7270101 and rs 1127354 showed high rates of AA and CC genotypes, respectively, suggesting that the study population are greatly prone to develop RBV-induced anemia. To our knowledge, this is the first report of the frequency of ITPA gene polymorphisms in a cohort of Brazilian patients coinfected with HCV/HIV. In HIV-1 infected adults on stable, contemporary ART, the prevalence of anemia was high [30] and in patients coinfected with HCV in RBV anemia may be more severe.

Because of the small number of study participants, it was not possible to evaluate the impact of SNPs in response to treatment of HCV. Besides that, studies about the SNP related to the response and toxicity to treatment in Brazil is recent. Similar to previous studies, they should be recommended in pretreatment period, when results could benefit not only the patients but also the public healthcare system, guiding the rational use of drugs in situations where treatment response rates are particularly low and adverse effects are high.

\section{References}

1. Kuehlkamp VM, Schuelter-Trevisol F (2013) Prevalence of human immunodeficiency virus/hepatitis $C$ virus co-infection in Brazil and associated factors: A review. Brazilian J Infect Dis 17: 455-463.

2. Ragni MV, Belle SH (2001) Impact of human immunodeficiency Virus infection on progression to end-stage liver disease in individuals with Hemophilia and Hepatitis C Virus infection. J Infect Dis 183: 1112-1115.
3. Benhamou Y, Bochet M, Di Martino V, Charlotte F, Azria F, et al. (1999) Liver fibrosis progression in human immunodeficiency virus and hepatitis $C$ virus coinfected patients. The Multivirc Group. Hepatology 30: 1054-1058.

4. Rockstroh JK, Mocroft A, Soriano V, Tural C, Losso MH, et al. (2005) Influence of hepatitis $\mathrm{C}$ virus infection on HIV-1 disease progression and response to highly active antiretroviral therapy. J Infect Dis 192: 992-1002.

5. CONITEC (2015) Protocolo clínico e diretrizes terapêuticas para hepatite $\mathrm{C}$ e coinfecções. Programa Nacional de DST/Aids, Ministério da Saúde - Dep DST Aids e Hepatites Virais, Brazil.

6. Strahotin CS, Babich M (2012) Hepatitis C variability, patterns of resistance and impact on therapy. Adv Virol 267483.

7. Estrabaud E, Appourchaux K, Bièche I, Carrat F, Lapalus M, et al. (2015) IFI35, mir-99a and HCV genotype to predict sustained virological response to pegylated-interferon plus ribavirin in chronic hepatitis C. PLoS One 10: e0121395.

8. Fellay J, Thompson AJ, Ge D, Gumbs CE, Urban TJ, et al. (2010) ITPA gene variants protect against anaemia in patients treated for chronic hepatitis $\mathrm{C}$ Nature 464: 405-408.

9. Akuta N, Sezaki H, Suzuki F, Fujiyama S, Kawamura Y, et al. (2016) Retreatment efficacy and predictors of ledipasvir plus sofosbuvir to HCV genotype 1 in Japan. J Med Virol .

10. Ferreira Cda S, Abreu RM, da Silva MC, Ferreira AS, Nasser PD, et al. (2013) A fast and cost-effective method for identifying a polymorphism of interleukin 28B related to hepatitis C. PLoS One 8: e78142.

11. Thompson AJ, Fellay J, Patel K, Tillmann HL, Naggie S, et al. (2010) Variants in the ITPA gene protect against ribavirin-induced hemolytic anemia and decrease the need for ribavirin dose reduction. Gastroenterology 139: 1181-1189.

12. Thompson AJ, Santoro R, Piazzolla V, Clark PJ, Naggie S, et al. (2011) Inosine triphosphatase genetic variants are protective against anemia during antivira therapy for HCV2/3 but do not decrease dose reductions of RBV or increase SVR. Hepatology 53: 389-395.

13. Imran M, Manzoor S, Ashraf J, Khalid M, Tariq M, et al. (2013) Role of vira and host factors in interferon based therapy of hepatitis $C$ virus infection. Virol J 10: 299.

14. Ge D, Fellay J, Thompson AJ, Simon JS, Shianna KV, et al. (2009) Genetic variation in IL28B predicts hepatitis C treatment-induced viral clearance. Nature 461: 399-401.

15. Fellay J, Thompson AJ, Ge D, Gumbs CE, Urban TJ, et al. (2010) ITPA gene variants protect against anaemia in patients treated for chronic hepatitis $\mathrm{C}$ Nature 464: 405-408.

16. Firdaus R, Biswas A, Saha K, Mukherjee A, Chaudhuri S, et al. (2014) Impact of host IL28B rs12979860, rs8099917 in interferon responsiveness and advanced liver disease in chronic genotype 3 hepatitis C patients. PLoS One 9: e99126.

17. De Nicola S, Aghemo A, Grazia Rumi M, Galmozzi E, Valenti L, et al. (2012) Interleukin $28 \mathrm{~B}$ polymorphism predicts pegylated interferon plus ribavirin treatment outcome in chronic hepatitis $C$ genotype 4 . Hepatology 55: 336-342.

18. Suppiah V, Moldovan M, Ahlenstiel G, Berg T, Weltman M, et al. (2009) IL28B is associated with response to chronic hepatitis $C$ interferon-alpha and ribavirin therapy. Nat Genet 41: 1100-1104.

19. Bertol BC, Moreira S, Garcia RF, Ferreira LE, Debortoli G, et al. (2015) IL28B gene polymorphisms in mono- and HIV-coinfected chronic hepatitis $C$ patients. Front Microbiol 6: 153

20. Martin MP, Qi Y, Goedert JJ, Hussain SK, Kirk GD, et al. (2010) IL28B polymorphism does not determine outcomes of hepatitis $B$ virus or HIV infection. J Infect Dis 202: 1749-1753.

21. Nattermann J, Vogel M, Nischalke HD, Danta M, Mauss S, et al. (2011) Genetic Variation in IL28B and Treatment-induced Clearance of Hepatitis C Virus in HIV-Positive Patients With Acute and Chronic Hepatitis C. J Infect Dis 203: 595-601.

22. Cao H, Hegele RA (2002) DNA polymorphisms in ITPA including basis of inosine triphosphatase deficiency. J Hum Genet 47: 620-622.

23. Maeda T, Sumi S, Ueta A, Ohkubo Y, Ito T, Marinaki AM, et al. (2005) Genetic basis of inosine triphosphate pyrophosphohydrolase deficiency in the Japanese population. Mol Genet Metab 85: 271-279. 
Citation: Avanzi VM, Vicente BA, Gomes-da-Silva MM, Vidal LRR, Nogueira MB, et al. (2016) IL28B and ITPA Single Nucleotide Polymorphisms in a Cohort of Patients with HCV and HCV/HIV, Southern Brazil. J AIDS Clin Res 7: 610. doi: 10.4172/2155-6113.1000610

Page 5 of 5

24. Keffe EB, Kowdley KV (2005) Hematologic side effects of interferon and ribavirin therapy. J Clin Gastroenterol 39: S3-S8.

25. Shipkova M, Lorenz K, Oellerich M, Wieland E, von Ahsen N (2006) Measurement of erythrocyte inosine triphosphate pyrophosphohydrolase (ITPA) activity by HPLC and correlation of ITPA genotype-phenotype in a Caucasian population. Clin Chem 52: 240-247.

26. Sakamoto N, Tanaka Y, Nakagawa M, Yatsuhashi H, Nishiguchi S, et al. (2010) ITPA gene variant protects against anemia induced by pegylated interferon-a and ribavirin therapy for Japanese patients with chronic hepatitis C. Hepatol Res 40: 1063-1071.

27.Kim JS, Ahn SM, Jung YK, Kwon OS, Kim YS, et al. (2013) The impact of inosine triphosphatase variants on hemoglobin level and sustained virologic response of chronic hepatitis C in Korean. J Korean Med Sci 28: $1213-1219$

28. Holmes JA, Roberts SK, Ali RJ, Dore GJ, Sievert W, et al. (2014) ITPA genotype protects against anemia during peginterferon and ribavirin therapy but does not influence virological response. Hepatology 59: 2152-2160.

29. Delvaux N, Costa VD Da, Costa MM Da, Villar LM, Coelho HSM, et al. (2015) Inosine triphosphatase allele frequency and association with ribavirin-induced anaemia in Brazilian patients receiving antiviral therapy for chronic hepatitis $\mathrm{C}$ Mem Inst Oswaldo Cruz 110: 636-643.

30. Lipshultz HM, Hileman CO, Ahuja S, Funderburg NT, McComsey GA (2015) Anaemia is associated with monocyte activation in HIV-infected adults on antiretroviral therapy. Antivir Ther 20: 521-527. 